\title{
Implementasi GRE Tunneling Menggunakan Open vSwitch Pada Jaringan Kampus
}

\author{
Mufid Ridlo Effendi ${ }^{1}$, Eki Ahmad Zaki Hamidi ${ }^{2}$, Andriansyah Saepulloh ${ }^{3}$ \\ ${ }^{1,2,3}$ Jurusan Teknik Elektro UIN Sunan Gunung Djati Bandung \\ ${ }^{1,2,3} \mathrm{JI}$. A.H. Nasution 105 Bandung \\ e-mail: ${ }^{1}$ mufid.ridlo@uinsgd.ac.id, ${ }^{2}$ ekiahmadzaki@uinsgd.ac.id, ${ }^{3}$ andriansyahsaepulloh17@gmail.com
}

\begin{abstract}
Abstrak - Perkembangan informasi yang pesat membuat penambahan jaringan baru harus dilakukan dengan cepat, efektif, dan efisien. Menghubungkan dua jaringan lokal yang berbeda wilayah dibutuhkan metoda yang tepat tanpa biaya yang besar. Salah satu metode jaringan untuk menghubungkan dua jaringan lokal yang berbeda wilayah tanpa terkoneksi langsung secara fisik yaitu menggunakan metode tunneling. Salah satu metode tunneling adalah GRE. Metode GRE menggunakan Open vSwitch dengan menggunakan simulator mininet dengan topologi jaringan kampus sederhana telah dilakukan pada penelitian ini. Simulasi ini menghasilkan hasil yang diinginkan dengan terkoneksinya tiap host pada jaringan kampus yang berbeda wilayah.
\end{abstract}

Kata kunci: Tunneling, GRE, Open vSwitch, Mininet

\section{Pendahuluan}

LAN (Local Area Network) merupakan jaringan paling kecil. Terdiri dari beberapa host yang dihubungkan menggunakan menggunakan switch layer 2 membentuk topologi star. Pada sebuah gedung, LAN dapat dibagi-bagi menjadi beberapa segmen untuk mengurangi collision domain. Koneksi antar gedung menjadikan interkoneksi antar LAN dalam satu administrasi. Salah satu interkoneksi antar LAN beberapa gedung yaitu pada kampus.

Interkoneksi pada suatu kampus dalam satu area masih memungkinkan menggunakan melalui physical layer secara langsung yaitu melakukan koneksi langsung menggunakan kabel. Suatu permasalah akan muncul jika terdapat kampus yang berbeda area atau beberapa gedung kampus di berbeda tempat, tetapi diinginkan masih jaringan lokal. Melakukan koneksi jaringan dengan koneksi langsung menggunakan kabel untuk area yang sangat jauh menjadi solusi yang tidak efektif dan efisien.

Terdapat teknologi jaringan yang dapat mengoneksikan jaringan lokal (LAN) yang berbeda area melalui jaringan publik (internet). Yaitu dengan cara tunneling, mengencapsulasi protokol IP dengan protokol tertentu dan diencapsulasi kembali oleh protokol IP kemudian dikirimkan melalui jaringan publik. Salah satu teknik tunneling yaitu GRE (Generic Routing Encapsulation) yang merupakan network layer over network layer. Tunneling merupakan solusi interkoneksi antar jaringan lokal yang dipisahkan oleh jarak jauh melalui jaringan publik [1].

Pada penelitian ini membahas tentang intrakoneksi antar kampus yang berbeda area yeng masih dalam satu jaringan lokal menggunakan protokol GRE. Perangkat yang digunakan adalah open vswitch yang merupakan switch virtual yang dapat dijalankan pada perangkat komputer dengan sistem operasi Linux. Untuk mengefisiensikan penggunaaan perangkat keras, dilakukan simulasi pada perangkat lunak mininet.

TELKA, Vol.3, No.2, November 2017, pp. 103 111

ISSN (e): 2540-9123

ISSN (p): 2502-1982 


\section{Dasar Teori}

\subsection{GRE Tunnel}

Tunneling merupakan metode encapsulasi, misalnya, suatu protokol (protokol X) diencapsulasi oleh protokol lain (protokol Y) saat dikirimkan sehingga protokol X transparent terhadap jaringan publik [2]. Terdapat beberapa protokol tunnel; GRE (Generic Routing Encapsulation) [3], L2TP (Layer 2 Tunneling Protocol) [4], PPTP (Point-to-Point Tunneling Protocol) [5], DVMRP (Distance Vector Multicast Routing Protocol) [6]. Gambar 1 memperlihatkan topologi sederhana tunneling.

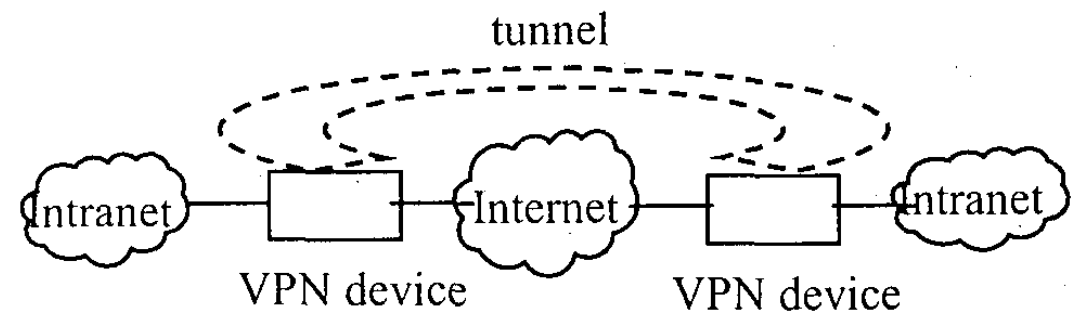

Gambar 1. Topologi sederhana tunneling [2]

GRE tunnel merupakan protokol tunneling yang dikembangkan oleh Cisco dan menyediakan encapsulasi untuk berbagai layer protokol jaringan pada jaringan point to point [7]. GRE tunnel dibangun antara router asal dan router tujuan sehingga paket yang di-forward melalui tunnel sebelumnya telah diencapsulasi oleh header yang baru (GRE header) [8]. Kelebihan GRE tunnel

1. Menghubungkan subnet yang tidak kontinyu

2. Penggunaan sumber daya yang rendah

3. Mendukung pesan unicast, multicast, dan broadcast

4. Dapat mengencapsulasi semua jenis protokol layer 3

GRE tunnel dapat digunakan pada kondisi :

- Menghubungkan jaringan yang tidak menggunakan protokol IP atau menghubungkan jaringan IP lokal antar area

- Merutekan paket IPv6 melalui jaringan IPv4

- Encrypt tarfik multicast [1].

Gambar 2 memperlihatkan header GRE tunnel.

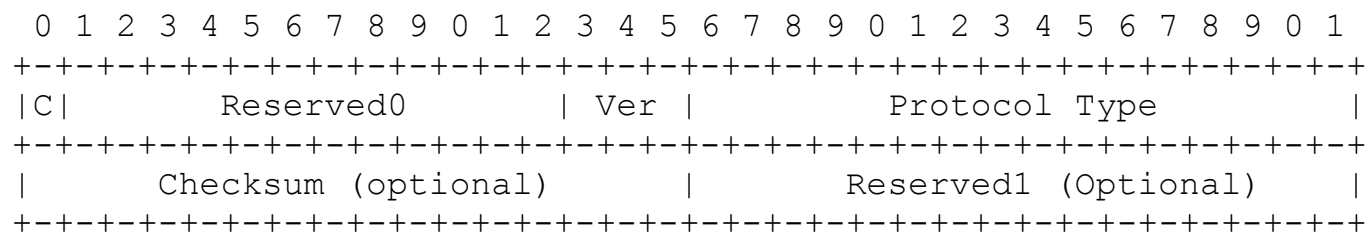

Gambar 2. GRE header [3] 


\subsection{Open vSwitch}

Open vSwitch merupakan perangkat lunak kode terbuka yang dirancang untuk digunakan sebagai vswitch (virtual switch) dalam lingkungan server virtual [9]. Open vSwitch dapat diinstall pada perangkat komputer atau perangkat keras khusus [10]. Open vSwitch dikembangkan oleh Nicira Network dan telah banyak digunakan karena kestabilannya dan dapat diprogram. Open vSwitch dijalankan sebagai modul pada kernel Linux menggantikan modul bridge [11]. Open vSwitch mendukung banyak managemen jaringan seperti NetFlow, sFLow, CLI dan lain sebagainya. Optimasi pada komputer (PC) telah dilakukan oleh [13], namun kinerjanya relatif lambat karena beban CPU yang berlebih. Pengujian kinerja pada PC telah dilakukan oleh [14]. Implementasi dan pengujian performa menggunakan NetFGA telah dilakukan [15].

Open vSwitch mendukung protokol OpenFlow [16], dimana Open vSwitch sebagai data plane dikontrol oleh controller sebagai control plane. Model komunikasi data plane dengan control plane diperlihatkan pada gambar 3 [6]. Data plane dapat dikontrol untuk melakukan QoS, tunneling, dan filtering rules. Dukungan pengontrolan jarak jauh membuat Open vSwitch dapat digunakan untuk melakukan proses migrasi kebijakan jaringan. Karena fleksibilitasnya, data plane pada Open vSwitch dapat dipartisi secara logik. Open vSwitch kombatibel dengan lingkungan virtual pada Linux seperti Xen, XenServer, KVM, dan QEMU [12].

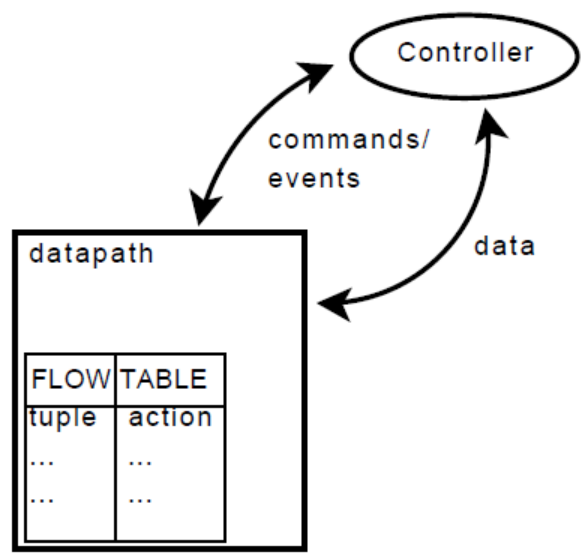

Gambar 3. Arsitektur Virtual Switch [10]

\subsection{Mininet}

Mininet merupakan sebuah system sebagai prototype untuk mengembangkan jaringan yang dijalankan pada sebuah perangkat komputer (laptop atau PC). Mininet dapat menampung ratusan node (switch, host, dan controller) dalam satu perangkat komputer. Mininet banyak digunakan untuk mengembangkan jaringan berbasis SDN. Pengguna dapat mengimplementasikan fitur baru pada jaringan yang dirancangnya, mengembangkanya, dan menjalankannya pada jaringan nyata. Mininet dijalankan pada Sistem Operasi Linux dengan menggunakan pemrograman python. Gambar 4 memperlihatkan contoh topologi sederhana yang dibangun menggunakan mininet [17].

Interaksi antara pengguna dengan mininet pada perangkat komputer melalui Command Line Interface (CLI) dapat melakukan konfigurasi pada seluruh jaringan yang dirancang dalam satu console. Pengembangan jaringan pada mininet secara manual melalui satu console akan memakan waktu dan ketelitian yang tinggi, untuk mempermudah pembuatan jaringan dapat digunakan script python pada sebuah file sehingga pembuatan jaringan akan lebih mudah dan jika kegagalan, penambahan node, penambahan fiture, dan lain sebagainya dapat langsung mengedit file script tersebut. 


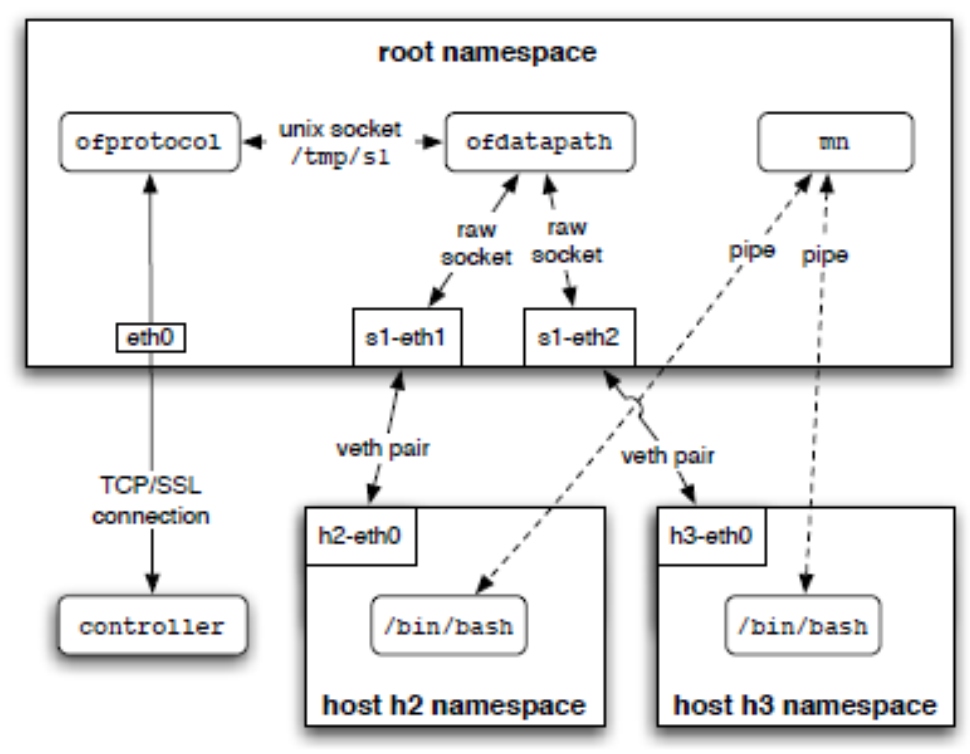

Gambar 4. Topologi sederhana yang dibangun menggunakan mininet [17]

\section{Perancangan Topologi Jaringan}

Topologi jaringan yang dirancang pada penelitian ini adalah topologi sederhana yang menghubungkan jaringan lokal (intranet) dengan jaringan lokal lainnya masih dalam satu subnet yang dipisahkan oleh jarak karena berbeda wilayah/area. Sebagai contoh adalah jaringan yang menghubungkan antara dua kampus yang berbeda wilayah. Tidak dibahas mengenai jaringan dalam kampus, tetapi pembahasan hanya pada cara menghubungkan satu kampus dengan kampus lainnya. Topologi tersebut digambarkan pada gambar 5.

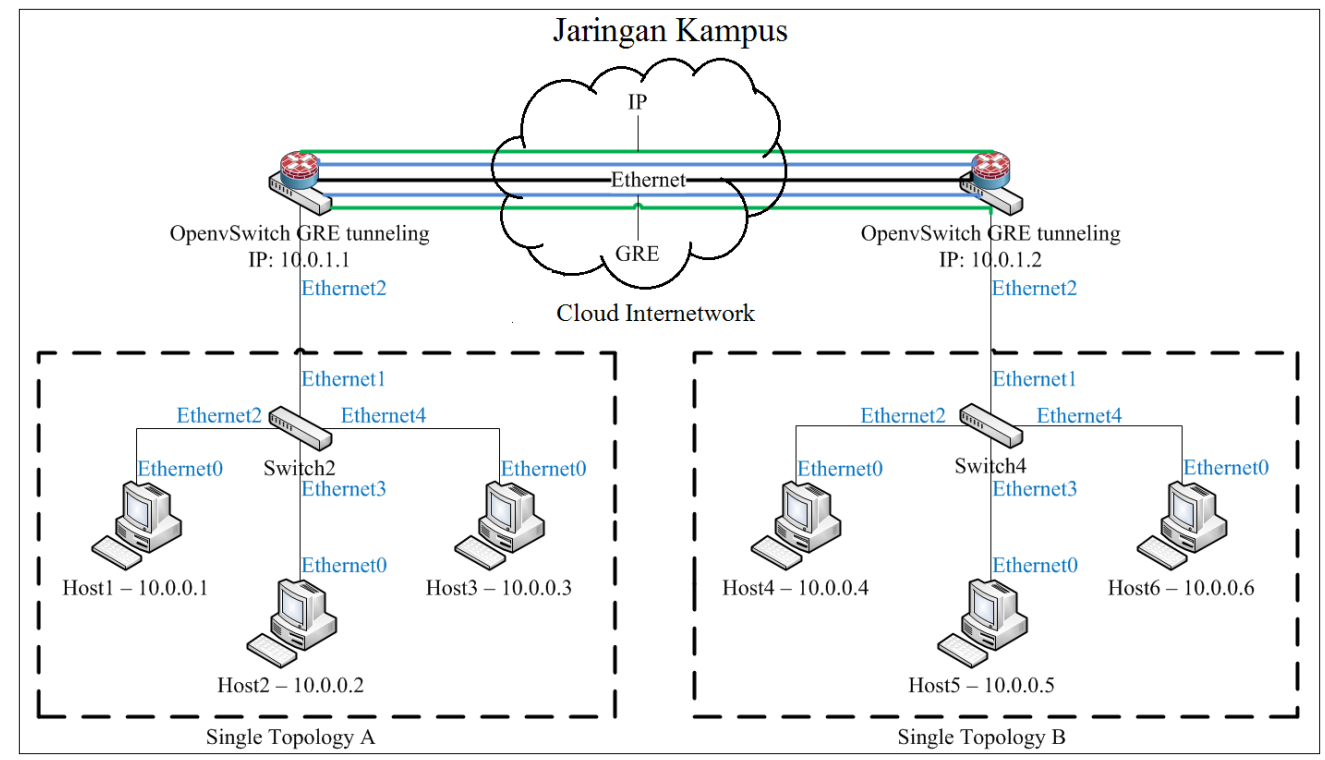

Gambar 5. Topologi jaringan antar kampus sederhana

Pada gambar 5, misalkan kampus A dan kampus B berada pada area yang berbeda. Untuk menghubungkan kedua kampus tersebut supaya jaringannya masih satu subnet digunakan metode tunneling menggunakan protokol GRE yang dijalankan pada Open vSwicth. Open vSwitch berdiri 
sendiri tidak terhubung dengan controller sehingga tidak digunakan protokol openflow untuk mengkonfigurasi Open vSwitch. Konfigurasi Open vSwitch dilakukan secara langsung dengan perintah manual yang ditulis dalam sebuah file berextensi python dan kemudian dijalankan pada console.

Sebagai simulasi internet, IP antar Open vSwitch dengan jaringan lokal dibedakan sehingga terjadi proses routing. Alamat IP Open vSwitch pada kampus A adalah 10.0.1.1 dan Open vSwitch pada kampus B adalah 10.0.1.2. Sementara alamat IP pada jaringan lokal menggunakan 10.0.0.0/24. Digunakan juga Open vSwitch pada tiap jaringan lokal yang berfungsi hanya sebagai switch layer 2.

\section{Perangkat Keras Dan Perangkat Lunak}

Implementasi topologi jaringan pada gambar 5 dilakukan pada perangkat keras laptop yang menjalankan sistem operasi Windows 7 64-Bit versi trial. Topologi dijalankan pada Mininet2.2.1-150420 yang berjalan pada sistem operasi Ubuntu-14.04-server-i386. Ubuntu server dijalankan pada Virtual Machine VirtualBox-5.0.16-105871-Win.

\section{Pengujian}

Pengujian awal yaitu melihat apakah konfigurasi yang sudah direncanakan sudah sesuai atau belum. Pada gambar 6 output konfigurasi pada Open vSwitch 1 yang menjalankan GRE tunnel.

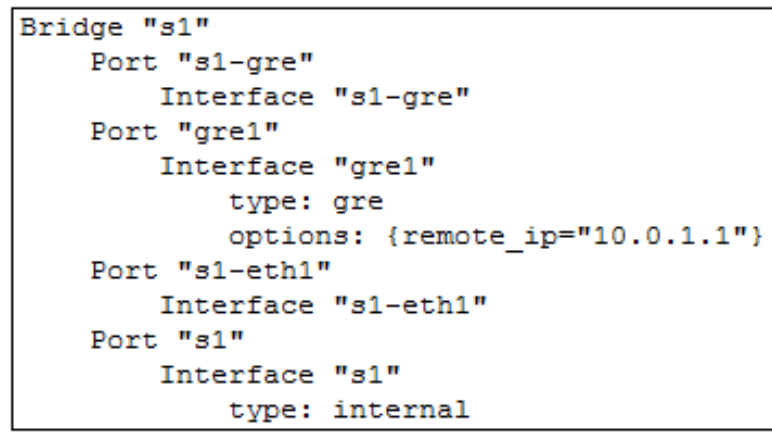

Gambar 6. Output konfigurasi Open vSwitch menjalankan GRE tunnel pada Open vSwitch 1

Gambar 7 merupakan output konfigurasi Open vSwitch 3 yang menjalankan GRE tunnel.

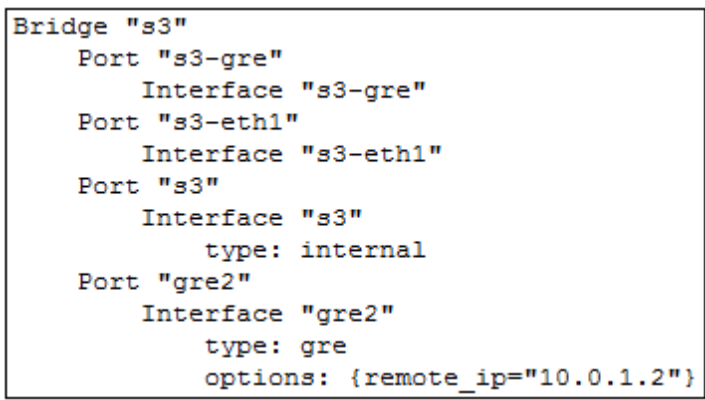

Gambar 7. Output konfigurasi Open vSwitch menjalankan GRE tunnel pada Open vSwitch 3

Gambar 8 dan 9 merupakan output konfigurasi pada Open vSwitch 2 dan Open vSwitch 4 yang berfungsi sebagai switch layer 2 . 


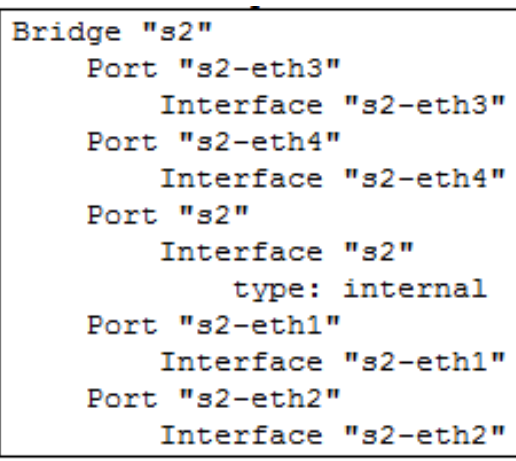

Gambar 8. Output konfigurasi Open vSwitch sebagai switch layer 2 pada Open vSwitch 2

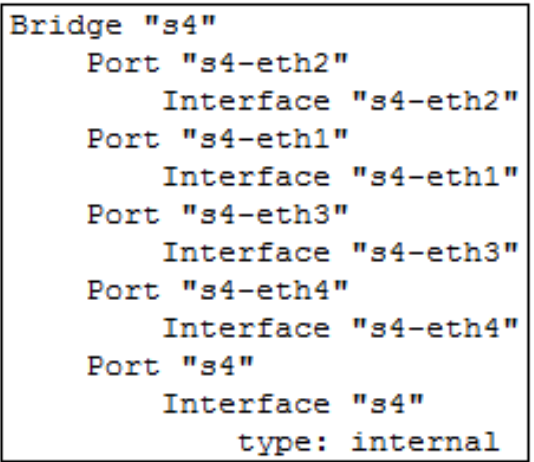

Gambar 9. Output konfigurasi Open vSwitch sebagai switch layer 2 pada Open vSwitch 4

Berikutnya adalah pengecekan konfigurasi jaringan keseluruhan, dapat dilihat pada gambar 10 .

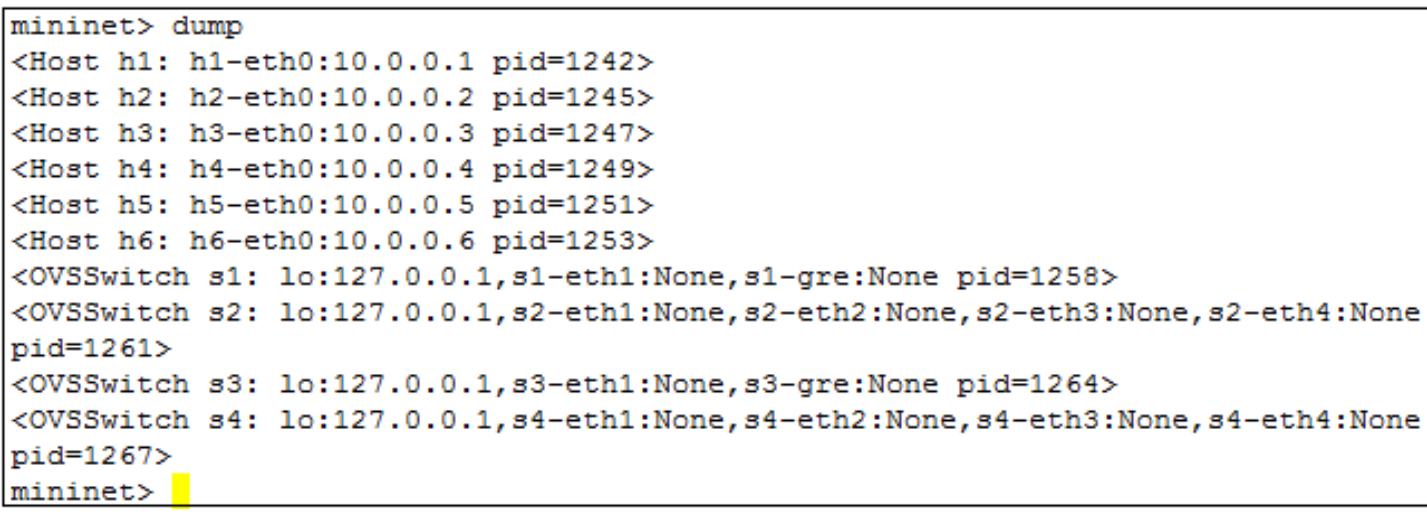

Gambar 10. Output konfigurasi jaringan

Pada gambar 10 terlihat semua node sudah terkonfigurasi sesuai dengan yang diharapkan.

Pengujian terakhir adalah menguji semua konektifitas antar host. Mininet memiliki tools khusus untuk menguji konektifitas antar semua host yaitu menggunakan perintah pingall. Output dari perintah pingall dapat dilihat pada gambar 11. 


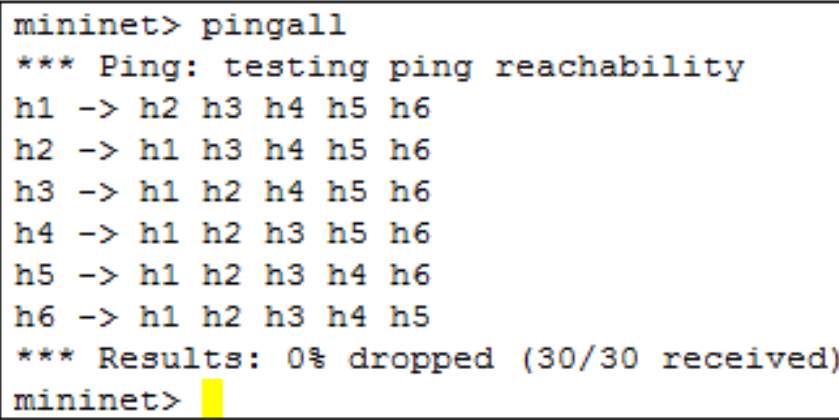

Gambar 11. Hasil pingall

Dengan perintah pingall pada mininet, semua host diuji koneksinya menggunakan protokol ICMP. Dari gambar 11 terlihat bahwa semua host terkoneksi satu dengan yang lainnya dilihat dari packet yang hilang $0 \%$. Hal tersebut menunjukan juga bahwa koneksi antara area yang berbeda terhubung dengan baik, terlihat h1 pada kampus A dapat terhubung dengan $\mathrm{h} 4$ pada kampus B. Artinya GRE tunnel menggunakan Open vSwitch dapat dilakukan dengan baik.

Pengujian lain yaitu dengan melakukan ping dari h1 ke h6 seperti pada gambar 12 dan koneksi client server antara h1 dan h6 seperti pada gambar 13.

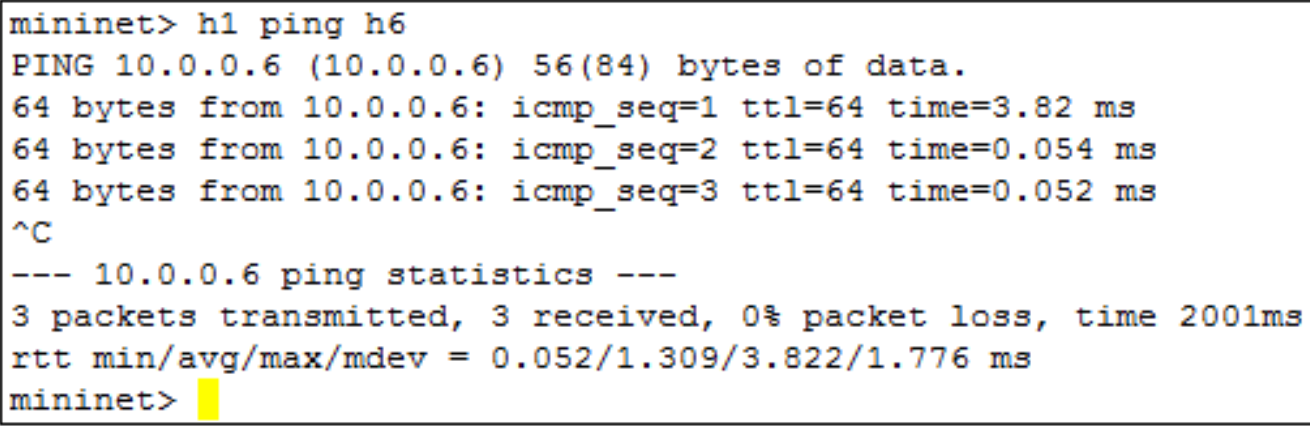

Gambar 12. Perintah ping antara h1 dan h6

Dari gambar 12, proses ping berjalan dengan baik terlihat semua paket yang dikirim oleh $\mathrm{h} 1$ diterima oleh h6. Dari gambar 13, h1 menjalankan web server sementara h6 sebagai client yang melakukan permintaan informasi. Proses koneksi client server antara h6 dan h1 berjalan baik dengan diterimanya kode http 200. 


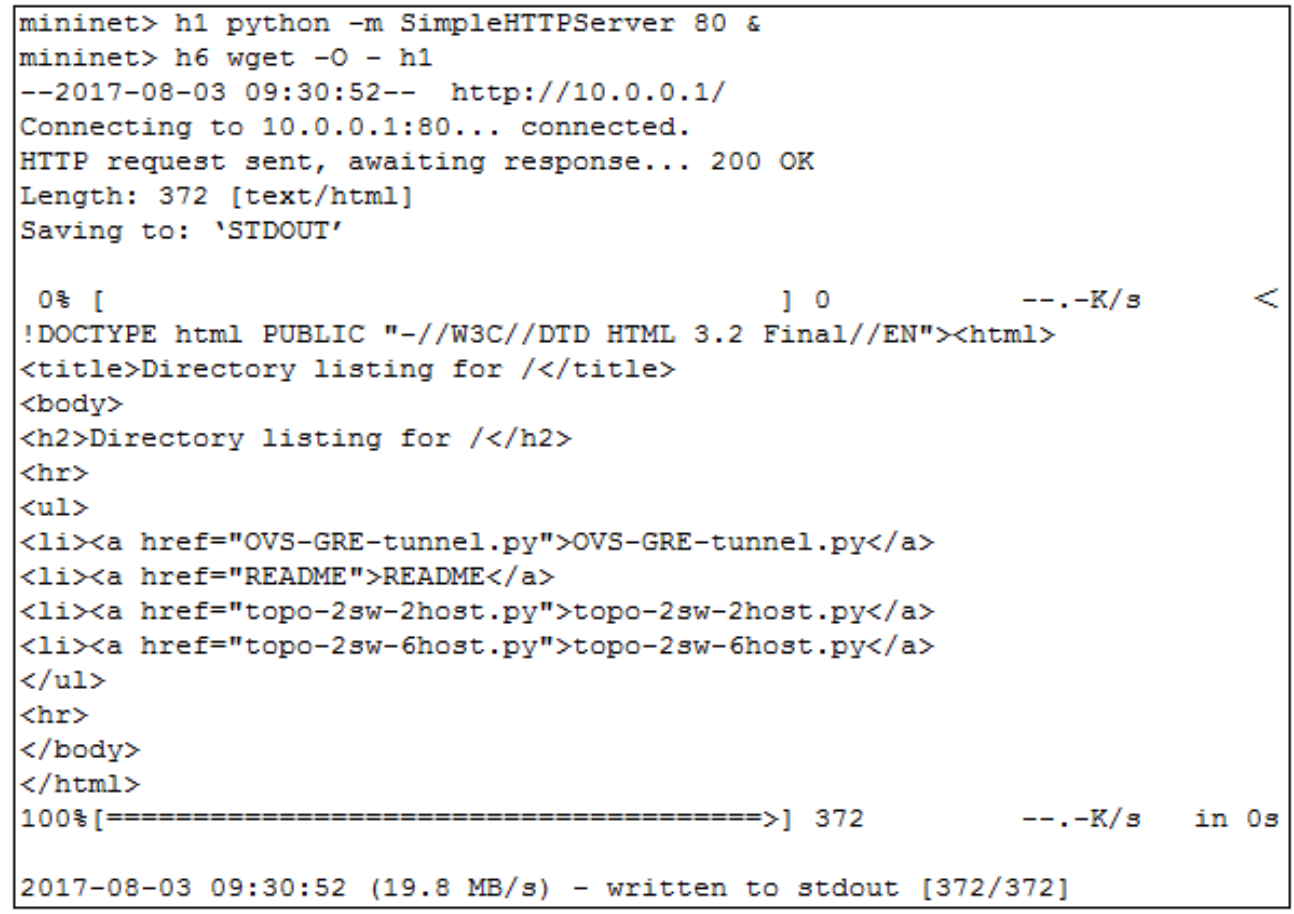

Gambar 13. Koneksi client server h1 dan h6

\section{Kesimpulan}

Hasil dari pengujian menunjukan semua host yang berada pada jaringan lokal yang satu dengan jaringan lokal yang lain dapat terhubung dengan baik. Pengujian dilakukan dengan melakukan proses ping dari satu host pada jaringan lokal satu dengan jaringan lokal lainnya. Dilakukan juga pengujian client server dengan hasil yang baik. Penggunaan protokol GRE pada Open vSwitch dapat berjalan baik sehingga dapat menjadi solusi penggunaan perangkat jaringan yang lebih murah dibandingkan dengan perangkat jaringan khusus yang menjalankan protokol GRE. Konfigurasi GRE pada Open vSwitch dapat dilakukan dengan mudah tanpa diperlukan konfigurasi tambahan yang rumit. Pada penelitian ini tidak dilakukan pengujian throughput karena jaringan yang digunakan merupakan simulasi pada mininet dimana kinerjanya bergantung pada perangkat komputer yang digunakan.

\section{Daftar Pustaka}

[1] Faycal Bensalah, Najib El Kamoun and Ayoub BAHNASSE, "Analytical performance and Evaluation of the Scalability of Layer 3 Tunneling Protocols: Case of Voice Traffic Over $I P^{\prime \prime}$, IJCSNS International Journal of Computer Science and Network Security. Vol.17, No. 4, pp. 361-369, April 2017.

[2] Zhao Aqun, Yuan Yuan, Ji Yi and Gu Guanqun, "Reserach on Tunneling Techniques in Virtual Private Networks", International Conference on Communication Technology Proceedings, Vol. 1, pp. 691-697, 2000.

[3] RFC2784. https://www.ietf.org/rfc/rfc2784.txt.

[4] RFC2661. https://www.ietf.org/rfc/rfc2661.txt.

[5] RFC2637. https://www.ietf.org/rfc/rfc2637.txt.

[6] RFC1075. https://www.ietf.org/rfc/rfc1075.txt. 
[7] Aria. Asadi Eskandar, Mahbubur. R. Syed, Bahareh. Zarei. M, "Performance Analysis of VOIP over GRE Tunnel", Computer Network and Information Security, pp. 1-9, Desember 2015.

[8] Paul Ferguson and Geoff Huston, "What is a VPN?", https://www.potaroo.net/papers/19983-vpn/vpn.pdf, Revision 1, April 1998.

[9] B. Pfaff and B. Davie, "The Open vSwitch Database Management Protocol", RFC 7047. 2013.

[10] Marta Carbone, Gaetano Catalli and Luigi Rizzo, "Improving the performance of Open vSwitch”, EuroBSDcon, May 30, 2011.

[11] Yunchun Li and Guodong Wang, "SDN-Based Switch Implementation on Network Processors", Communications and Network, Vol 5, pp. 434-437, June 2013.

[12] B. Pfaff, J. Pettit, T. Koponen, K. Amidon, M. Casado, and S. Shenker, "Extending Networking into the Virtualization Layer", In Proc. of HotNets, October. 2009.

[13] Voravit Tanyingyong, Markus Hidell and Peter Sjodin, "Using Hardware Classification to Improve PC-Based OpenFlow Switching”, IEEE 12th International Conference on High Performance Switching and Routing, July 2011.

[14] Andrea Bianco, Robert Birke, Luca Giraudo, Manuel Palacin, "Openflow Switching: Data Plane Performance”, IEEE International Conference on Communications (ICC), pp. 1-5, 2010.

[15] Jad Naous, David Erickson, G. Adam Covington, Guido Appenzeller, and Nick McKeown, "Implementing an OpenFlow Switch on the Netfpga Platform," ANCS: Proceedings of the 4th ACM/IEEE Symposium on Architectures for Networking and Communications Systems, pp. 1-9, November 2008.

[16] OpenFlow. https://www.opennetworking.org.

[17] Bob Lantz, Brandon Heller, Nick McKeown, "A Network in a Laptop: Rapid Prototyping for Software-Defined Networks”, SIGCOMM, August 2015.

[18] Eueung Mulyana, "Buku Komunitas SDN-RG", GitBook. 